\title{
控制降水梯度对荒漠草原优势植物叶功能性状及土壤 养分的影响
}

\author{
吴旭东 ${ }^{*}$, 季 波, 何建龙, 任小玢, 俞鸿千, 王占军 \\ 宁夏农林科学院荒漠化防治研究所, 银川 750002
}

\begin{abstract}
摘要:探究植物叶功能性状随降水梯度的变化规律,对揭示干旱区优势植物对环境变化的响应和适应策略至关重要。以盐池荒 漠草原为研究对象,采用遮雨棚和喷灌系统控制降水梯度, 分析了优势植物蒙古冰草 (Agropyron mongolicum)、短花针茅 (Stipa breviflora) 及达乌里胡枝子 (Lespedeza davurica) 叶功能性状变异, 以及土壤水分、养分和微生物特性与响应性状间的相关关系。 结果表明: HW (增水 50\%) 处理下 3 个植物 LA (叶面积)、LDMC(干物质含量) 显著增大, LW 处理(减水 $50 \%$ )下短花针茅和达 乌里胡枝子 LA、LDMC 显著减小,降水处理对短花针茅和达乌里胡枝子 SLA (比叶面积) 影响不显著, LW 处理显著提高了蒙古 冰草 SLA; LW 处理显著提高了蒙古冰草和短花针茅 $\mathrm{LNC}$ (叶氮含量) 和 $\mathrm{LPC}$ (叶磷含量) ; HW 显著降低了土壤 $\mathrm{C} 、 \mathrm{~N}$ 含量, $\mathrm{LW}$ 和 $\mathrm{HW}$ 均显著减少了真菌数量, 而放线菌数量、微生物生物量 $\mathrm{C} 、 \mathrm{~N}$ 显著增加; 3 种优势植物 $\mathrm{LA}$ 均与土壤水分显著正相关, 蒙古冰 草和短花针茅通过提高 SLA、LNC 及 LNP 来适应干旱生境, 蒙古冰草和短花针茅 LNC 及 LNP 是表征土壤 P、微生物生物量有效 性的关键指标, 达乌里胡枝子通过自我调节养分利用策略来适应 $\mathrm{C} 、 \mathrm{~N} 、 \mathrm{P}$ 含量和微生物活性较低的生境, 从而决定其在群落中 的优势地位。
\end{abstract}

关键词: 荒漠草原; 优势种; 叶功能性状;土壤养分; 降水梯度

\section{The effects of precipitation gradient control on the leaf functional traits and soil nutrients of the dominant plants in a desert steppe}

\author{
WU Xudong* , JI Bo, HE Jianlong, REN Xiaobin, YU Hongqian, WANG Zhanjun \\ Institute of Desertification Control, Ningxia Academy of Agricultural and Forestry Sciences, Yinchuan 750002, China
}

\begin{abstract}
Investigating how leaf functional traits change with precipitation gradients is important for understanding the dominant plant adaptation strategies to cope with environmental change. The functional traits of the desert steppe dominant plants, Agropyron mongolicum, Stipa breviflora, and Lespedeza davurica varieties, were analyzed, as were the correlations between soil moisture, nutrients, microbial characteristics, and the response traits. This field study was conducted at Dashuikeng Grassland Research Station, Yanchi County $\left(106^{\circ} 58^{\prime} \mathrm{E}, 37^{\circ} 24^{\prime} \mathrm{N}\right.$, average elevation, $\left.1560 \mathrm{~m}\right)$, Ningxia Hui Autonomous Region, China. This region covers a large ecosystem of desert steppe that characterized by low rainfall and uneven precipitation, along the southwest edge of the Mu Us Sandy Land. In the study desert steppe area on the southeastern margin of the Tengger Desert, the average annual precipitation was only $298.3 \mathrm{~mm}$ during the 60 years from 1959 to 2019. The precipitation was regulated by the measurement of artificial rain using rainwater shed and sprinkler irrigation technologies, in order to evaluate precipitation effects on the biological soil crusts in desert steppe compared with natural

基金项目:国家重点研发计划(2016YFC0400305); 宁夏回族自治区重点研发计划 (引才专项) (2018BEB04016);第四批宁夏青年科技人才推举 工程项目 (TJGC2019066) ; 宁夏农林科学院科技平台建设提升项目( NKYP-19-06)

收稿日期: 2020-03-14; 网络出版日期:2021-01-27

* 通讯作者 Corresponding author.E-mail: wxd2008lovejz@126.com
\end{abstract}


precipitation. 12 precipitation treatments $(6 \mathrm{~m} \times 6 \mathrm{~m})$ were set up at the test station in early March 2018 , where $3 \mathrm{~m}$ wide buffer zone was designed between each plot. Control conditions of precipitation were designed via the shelter and sprinkler irrigation system, including 3 precipitation treatments, natural precipitation ( CK), low water treatment ( LW, 50\% water reduction), and high water treatment ( $\mathrm{HW}, 50 \%$ increase). Each precipitation treatment has 4 replicates. In the same period, small weather stations were set up in the test area. TRIME-PICO TDR Portable Soil Moisture Meter (made in Germany) was used for the data collection of precipitation in the soil water depth of $10 \mathrm{~cm}$. The results showed that the leaf area (LA) and leaf dry matter content (LDMC) of all plants increased significantly with high water treatment ( HW, 50\% increase), and low water treatment ( $\mathrm{LW}, 50 \%$ water reduction) significantly reduced the LA and LDMC of Stipa breviflora and Lespedeza davurica. Precipitation had no effect on the specific leaf area (SLA) of Stipa breviflora but the SLA of Agropyron mongolicum significantly increased with the LW treatment. LW significantly improved the leaf nitrogen content ( LNC) and leaf phosphorus content (LPC) of Agropyron mongolicum and Stipa breviflora. In Agropyron mongolicum and Stipa breviflora, LW significantly improved the leaf nitrogen content ( LNC) and leaf phosphorus content (LPC). HW significantly reduced the soil carbon $(\mathrm{C})$ and nitrogen $(\mathrm{N})$ content, and both treatments significantly reduced the number of fungi, but the number of actinomycetes and the soil microbial biomass carbon ( SMBC) and nitrogen ( SMBN) significantly increased. All plants had a significant positive correlation between LA and soil moisture. Agropyron mongolicum and Stipa breviflora adapted to an arid habitat by increasing SLA, LNC, and LPC, and the key indicators of soil phosphorus (P) and the effectiveness of microbial biomass may be LNC and LPC. Lespedeza davurica used self-regulating nutrient utilization strategies to adapt to habitats with low $\mathrm{C}, \mathrm{N}$, and $\mathrm{P}$ and low microbial activity, thereby confirming its dominant position in the community.

Key Words : desert steppe; dominant species; leaf functional trait; soil nutrients ; precipitation gradient

气候变化对陆地生态系统的影响及反馈是全球变化研究的重要内容 ${ }^{[1]}$, 其中, 降水格局对生态系统的影 响及生态系统如何响应这种变化成为现今生态学研究的重要内容 ${ }^{[2]}$ 。据报道 ${ }^{[3]}$, 未来全球强降雨频率和强 度都会增加,局部地区频繁的干旱事件将对生态系统生物多样性、生产力、物质循环以及土壤微生物群落等产 生深远的影响 ${ }^{[4]}$ 。干旱与半干旱区是全球气候变化的敏感区域,降水是决定该区域生态系统结构和功能的 关键环境因子 ${ }^{[5]}$, 而约占全球陆地面积 $30 \%$ 的草地生态系统, 主要分布于干旱及半干旱地区 ${ }^{[6]}$, 具有对气候 变化敏感、生产力年际波动大的特点, 对区域生态系统的稳定起着关键作用 ${ }^{[7-8]}$ 。

近年来, 国内外学者开展了一系列针对草地群落结构特征、数量特征以及生产力如何响应降水格局变化 的研究工作, 主要集中在降雨格局对草地生产力 ${ }^{[9-14]}$ 、植物物候 ${ }^{[15]}$ 、内部物质循环 ${ }^{[16]}$ 、群落结构 ${ }^{[17]}$ 、物种多样 性 ${ }^{[18]}$ 、调落物分解以及地下根系分布特征 ${ }^{[19]}$ 等方面。然而, 由于降雨格局同样改变植物群落营养成分以及 生物地球化学循环过程 ${ }^{[20-22]}$, 针对草地优势种和植物功能型与降水关系的研究相对薄弱 ${ }^{[23-25]}$, 在草地生态系 统稳定性研究中, 找出能反映植物对降水梯度响应的性状指标、阈值响应点及适应机制越来越重要 ${ }^{[26-27]}$ 。

植物对环境的响应和适应策略一直是生态学研究的核心问题。优势物种的功能性状是生态系统过程和 功能的主要决定者, 并反映植物所在生境的功能特征 ${ }^{[28-31]}$ 。优势植物通过改变自身的某些功能性状来适应 环境变化,并形成了不同的生存策略,基于植物功能性状的植被-环境关系研究, 能更好地揭示植物对环境的 响应和适应规律。叶片作为与环境接触面积最大、对环境变化最为敏感的植物器官, 其性状与植物对资源的 利用能力和效率联系紧密, 能够反映植物适应环境变化所形成的生存对策 ${ }^{[32-34]}$ 。分布在干旱半干旱区的优 势植物种是对空间异质性或环境变化适应进化的结果 ${ }^{[35]}$, 在荒漠草原植被演替过程中具有重要地位, 特别是 一些耐旱、多年生物种, 是该地区天然草地的主要建群种, 针对其环境适应特性等研究较少。基于此, 本研究 选择 3 个极端降水梯度, 以优势种或建群种为研究对象, 分析不同降水梯度下植物叶面积、干物质含量、比叶 面积、N、P 含量的差异, 通过植物叶片功能性状与土壤养分、水分、微生物及气象因子间的关系分析, 旨在揭 
示荒漠草原优势植物对异质环境的适应性变化,进而阐释荒漠草原优势植物在不同降水区的分布格局,研究 工作可为全球气候变化背景下荒漠生态系统的科学管理提供一定的科学依据。

\section{1 材料和方法}

\section{1 研究区概况}

研究区位于宁夏回族自治区盐池县大水坑草原研究站 (东经 $106^{\circ} 58^{\prime}$, 北纬 $37^{\circ} 24^{\prime}$, 平均海拔 $1560 \mathrm{~m}$ )。 研究站位于毛乌素沙地南缘, 属干旱和半干旱过渡带, 典型的中温带大陆性气候, 年平均气温为 $7.5{ }^{\circ} \mathrm{C}$, 降雨 集中在 6 月至 9 月,占总降雨量的 $80 \%$ 以上,近 60 年平均降雨量约为 $298.3 \mathrm{~mm}$, 蒸发量超过 $2700 \mathrm{~mm}$, 年平均 无霜期是 $164 \mathrm{~d}$ 。土壤类型以易沙化的淡灰钙土和风沙土为主。自 2001 年以来, 研究区一直处于围封状态。 植被类型主要是沙生植被和荒漠植被, 优势种有蒙古冰草 (Agropyron mongolicum) 、短花针茅 ( Stipa breviflora)、达乌里胡枝子(Lespedeza davurica) 和猪毛蒿(Artemisia scoparia)。

\section{2 试验设计}

2018 年 3 月上旬, 在研究站设置降雨量增减的观测样地, 采用单因素完全随机试验, 设置了 3 种降水处 理: 自然降水 (CK)、减水 $50 \%$ 、增水 $50 \%$,每种降雨处理设置 4 个 $6 \mathrm{~m} \times 6 \mathrm{~m}$ 的重复小区(图 1 ), 每个小区周围 设置了 $1 \mathrm{~m}$ 深隔水层, 小区间设计 $3 \mathrm{~m}$ 宽的缓冲区。减雨试验装置是由支撑架、截雨槽、集雨箱组成, 根据塑 料板间隔宽度截留部分降雨量来实现, 减雨收集的雨水汇集于 $1000 \mathrm{~L}$ 的集雨箱中, 迅速利用水泵和喷灌系统 将收集的雨水均匀喷酒至对应的增水试验区, 水分控制时间为 2019 年 1 月中旬到 9 月中旬, 控制试验期累计 降雨量为 $289 \mathrm{~mm}, 3$ 种降水处理分别用 CK (观测期降水量 $289 \mathrm{~mm}$ )、 HW (降水量 $+50 \%, 433.5 \mathrm{~mm}$ )、 LW (降 水量 $-50 \%, 144.5 \mathrm{~mm}$ ) 表示。

\section{3 取样和测定方法}

2019 年 9 月,在草地植物生长最旺盛期 (降雨集中在 6-9 月份), 在每个降水处理区选择 5 个正方形方 格 $(1 \mathrm{~m} \times 1 \mathrm{~m})$, 采集方格中最新鲜、完全展开且没有病虫害的优势植物种叶片 10 片及 $0-10 \mathrm{~cm}$ 土层土壤进 行营养分析。本研究选择优势植物种蒙古冰草 (Agr)、短花针茅 (Sti) 和达乌里胡枝子 (Les) 作为研究对象, 叶 形态性状指标主要包括叶面积 (LA, Leaf area)、叶干物质 (LDMC, Leaf dry matter content)、比叶面积 (SLA, Specific leaf area)、叶片 $\mathrm{N}$ 含量 (LNC, Leaf nitrogen content)、P 含量 (LPC, Leaf phosphorus content) ${ }^{[36]}$ 。AM350 便携式叶面积仪 (英国) 测定叶面积, 然后, $80^{\circ} \mathrm{C}$ 烘干 $24 \mathrm{~h}$ 至恒质量, 称质量。比叶面积采用公式 SLA $=\mathrm{LA} /$ LM 计算。每个降水处理区同一层次的土样均匀混合, 四分法取样, 所取土壤样品剔除可见的植物残体和石 块后分成两份, 其中一份风干过篮测定土壤有机碳、总氮和总磷 ${ }^{[36]}$, 另外一部分鲜土用于分析土壤微生物生 物量碳( SMBC, Soil microbial biomass carbon)、氮( SMBN, Soil microbial biomass nitrogen) 及其微生物群落丰富 度 ${ }^{[37]}$ 。采用研究站 GMX600 MaxiMet 微型气象站(英国 GILL 公司) 进行降雨量数据收集, 采用 ET100 土壤温 湿度观测系统 (中国) 监测土壤水分。

\section{4 数据处理}

使用 SAS 8.0 软件对不同降水处理叶片功能性状及土壤数据进行单因素 Anova 统计分析, 并对叶片功能 性状与土壤因子进行 Pearson 相关性分析, 使用 Origin 9.0 软件进行图表绘制。

\section{2 结果与分析}

\section{1 降水水平对优势植物种叶功能性状的影响}

降水量变化对优势植物种蒙古冰草、短花针茅和达乌里胡枝子的叶面积 (LA)、干物质含量 (LDMC)、比 叶面积 (SLA)、叶氮含量 ( LNC)、叶磷含量 ( LPC) 及叶片 N/P 均产生显著影响 (图 2)。增水 $50 \%$ ( HW) 处理 下 3 个优势植物种 LA 显著增大, 减水 $50 \%(\mathrm{LW})$ 处理下短花针茅和达乌里胡枝子 LA 显著减小, $\mathrm{LW}$ 对蒙古 冰草 LA 影响不显著; HW 处理下优势植物 LDMC 显著高于 CK 和 LW 处理, LW 处理下短花针茅和达乌里胡 


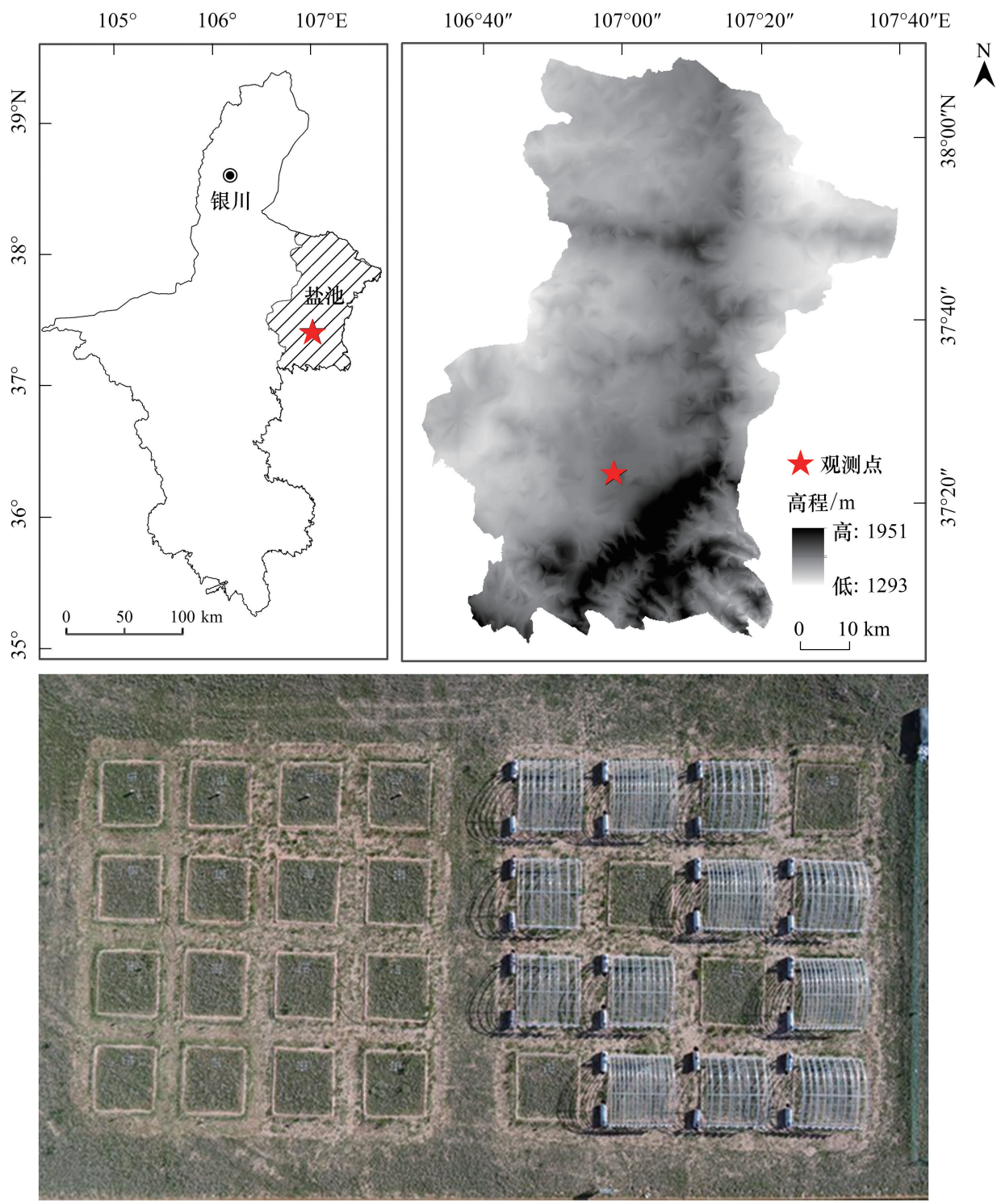

图 1 研究区和试验布设

Fig.1 Study area location and test layout

枝子 LDMC 显著下降; HW 和 LW 处理对短花针茅和达乌里胡枝子 SLA 影响不显著, 而 LW 处理通过提高蒙 古冰草 LDMC 而显著增大其 SLA; 与 CK 相比较, HW 和 LW 处理均显著提高了蒙古冰草和短花针茅 $\mathrm{LNC}$ 含 量, 但在 LW 处理下 LNC 含量达到最高,达乌里胡枝子 LNC 含量对降水变化的响应却表现为 $H W>C K>L W$; 与 LNC 含量相似, HW 和 LW 均不同程度提高了蒙古冰草和短花针茅 LPC 含量, 氮 LW 处理下 LPC 增加最为 显著, 在 $\mathrm{CK}$ 处理下最小, 达乌里胡枝子 LPC 含量对降水变化的响应却表现为 $\mathrm{CK}>\mathrm{LW}=\mathrm{HW}$; 另外, $\mathrm{LW}$ 处理 显著提高了蒙古冰草和达乌里胡枝子叶片 N/P, 而 HW 处理对其影响不显著, HW 处理显著增大了短花针茅 叶片 $\mathrm{N} / \mathrm{P}$, 而 LW 处理对其影响不显著。

2.2 降水水平对土壤碳、氮、磷及水分含量的影响

不同降水处理对 0-10 cm 土壤水分 (SW)、有机碳 $(S O C)$ 、全氮 $(S T N)$ 和全磷 $(S T P)$ 均表现出显著影响 (表 1)。 $\mathrm{LW}$ 处理显著降低了 $\mathrm{SW}, \mathrm{HW}$ 处理下 $\mathrm{SW}$ 最高, 与 $\mathrm{CK}$ 相比较, $\mathrm{LW}$ 处理对 SOC 和 STN 含量影响不显 著, 而 HW 显著降低了 SOC 和 STN 含量, 在自然降雨的基础上, 降水增加 50\%, SOC 和 STN 含量分别下降了 $5.07 \%$ 和 $8.89 \%$, 增加降水对表层土壤碳、氮矿化作用显著, LW 处理下表层 STP 含量最高, 增加降水对 STP 含 量影响不显著。 

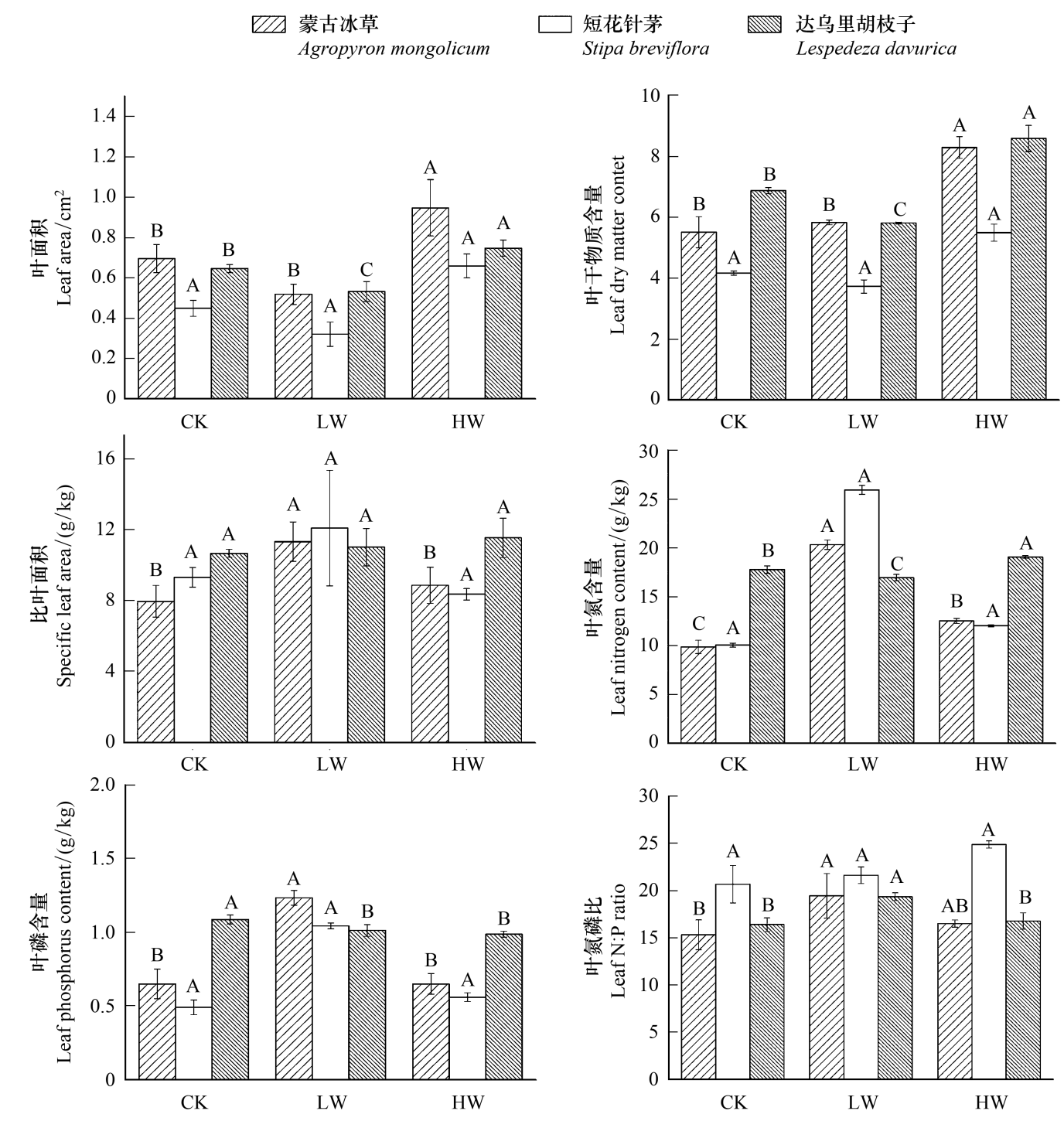

图 2 不同降水水平下优势种植物叶片功能性状变异

Fig.2 Leaf functional trait variation of dominant plants under different rainfall levels

CK : 自然降水量, Control check; HW: 降水量增加 50\%, High water addition treatment; LW: 降水量减少 50\%, Low water addition treatment; 不 同大写字母表示物种间显著差异 $(P<0.01)$

表 1 不同降水水平下土壤碳,氮、磷和水分含量

Table 1 Characteristics of soil C、N、P and soil water content among different precipitation levels

\begin{tabular}{cclcc}
\hline $\begin{array}{c}\text { 降水水平 } \\
\text { Precipitation levels }\end{array}$ & SW $/ \%$ & SOC $/(\mathrm{g} / \mathrm{kg})$ & $\mathrm{STN} /(\mathrm{g} / \mathrm{kg})$ & $\mathrm{STP} /(\mathrm{g} / \mathrm{kg})$ \\
\hline $\mathrm{CK}$ & $8.94 \pm 0.87 \mathrm{~B}$ & $6.51 \pm 0.11 \mathrm{~A}$ & $0.45 \pm 0.01 \mathrm{~A}$ & $0.30 \pm 0.01 \mathrm{~B}$ \\
$\mathrm{LW}$ & $4.14 \pm 0.73 \mathrm{C}$ & $6.41 \pm 0.08 \mathrm{AB}$ & $0.43 \pm 0.01 \mathrm{~A}$ & $0.35 \pm 0.01 \mathrm{~A}$ \\
$\mathrm{HW}$ & $10.90 \pm 1.11 \mathrm{~A}$ & $6.18 \pm 0.19 \mathrm{~B}$ & $0.41 \pm 0.01 \mathrm{~B}$ & $0.28 \pm 0.02 \mathrm{~B}$ \\
\hline
\end{tabular}

不同大写字母表示物种间显著差异 $(P<0.01)$; CK: 自然降水量 Control check; HW : 降水量增加 50\% High water addition treatment; LW : 降 水量减少 50\% Low water addition treatment; SW: 土壤含水量 Soil water content; SOC: 土壤有机碳 Soil organic carbon; STN: 土壤全氮 Soil total nitrogen; STP: 土壤全磷 Soil total phosphorus

2.3 降水水平对土壤微生物特性的影响

土壤微生物数量和群落组成是衡量土壤质量和肥力的一个重要指标, 土壤微生物生物量作为土壤中植物 
有效养分的“源” 和“库”, 是土壤营养元素和土转化与循环过程的有效动力, 在土壤肥沃性和植物营养中起非 常重要作用。通过不同降水处理下土壤细菌、真菌、放线菌数量变化可以看出 (表 2), 与自然降雨量 CK 相 比,增水处理 $\mathrm{HW}$ 和减水处理 $\mathrm{LW}$ 均显著降低了真菌数量, 同时极显著增加了放线菌数量, 增减水对细菌数量 影响不显著。比较自然降水 $\mathrm{CK}, \mathrm{HW}$ 和 $\mathrm{LW}$ 处理下真菌数量分别减少了 $75.84 \%$ 和 $55.06 \%$, 而放线菌数量分 别增加了 28.6 倍和 24.2 倍。同时, HW 和 LW 处理均显著提高了土壤微生物生物量碳( SMBC)、氮( SMBN), 与 $\mathrm{CK}$ 相比较, $\mathrm{HW}$ 和 $\mathrm{LW}$ 处理下 $\mathrm{SMBC}$ 分别提高了 $8.26 \%$ 和 $111.95 \%, \mathrm{SMBN}$ 分别显著提高了 $26.06 \%$ 和 $101.97 \%$ 。结合表 1 发现, 减水处理显著降低了土壤含水量, 提高了养分含量, 进而对生活在土壤中的主要微 生物类群数量和微生物量碳氮产生了不同的影响。

表 2 降水量对土壤微生物生物量碳, 氮含量及微生物数量的影响

Table 2 Effects of precipitation levels on soil microbial biomass carbon, nitrogen and soil microbe number

\begin{tabular}{cccccc}
\hline $\begin{array}{c}\text { 降水水平 } \\
\text { Precipitation levels }\end{array}$ & $\begin{array}{c}\mathrm{SMBC} / \\
(\mathrm{g} / \mathrm{kg})\end{array}$ & $\begin{array}{c}\text { SMBN/ } \\
(\mathrm{g} / \mathrm{kg})\end{array}$ & $\begin{array}{c}\text { 细菌数量 } \times 10^{5} \\
\text { Soil bacteria }\end{array}$ & $\begin{array}{c}\text { 真菌数量 } \times 10^{7} \\
\text { Soil fungus }\end{array}$ & $\begin{array}{c}\text { 放线菌数量 } \times 10^{4} \\
\text { Soil actinomyete }\end{array}$ \\
\hline CK & $149.95 \pm 3.71 \mathrm{C}$ & $21.87 \pm 0.38 \mathrm{C}$ & $3.76 \pm 0.93 \mathrm{~A}$ & $1.78 \pm 0.21 \mathrm{~A}$ & $0.09 \pm 0.02 \mathrm{~B}$ \\
$\mathrm{LW}$ & $317.82 \pm 6.36 \mathrm{~A}$ & $44.17 \pm 0.64 \mathrm{~A}$ & $3.90 \pm 0.42 \mathrm{~A}$ & $0.80 \pm 0.14 \mathrm{~B}$ & $2.66 \pm 0.52 \mathrm{~A}$ \\
$\mathrm{HW}$ & $162.33 \pm 3.80 \mathrm{~B}$ & $27.57 \pm 0.51 \mathrm{~B}$ & $3.35 \pm 0.84 \mathrm{~A}$ & $0.43 \pm 0.09 \mathrm{C}$ & $2.27 \pm 0.63 \mathrm{~A}$ \\
\hline
\end{tabular}

SMBC: 土壤微生物生物量碳 Soil microbial biomass carbon; SMBN : 土壤微生物生物量氮 Soil microbial biomass nitrogen

\section{4 优势种叶片功能性状与土壤因子的相关性分析}

降水量变化对本研究测定的优势植物种蒙古冰草、短花针茅和达乌里胡枝子的叶片功能性状、表层土壤 养分和微生物群落及微生物生物量均有显著的影响。指标间相关性分析显示 (表 3), 土壤水分 (SW) 与蒙古 冰草 LA 呈极显著正相关关系 $(P<0.01)$, 与 SLA、LNC 及 LNP 呈极显著负相关关系 $(P<0.01)$, 土壤有机碳 (SOC) 与蒙古冰草 LA 和 LDMC 分别呈显著 $(P<0.05)$ 和极显著 $(P<0.01)$ 负相关关系, 土壤全氮 $(\mathrm{STN})$ 也与 LDMC 分别呈极显著 $(P<0.01)$ 负相关关系, 土壤全磷 $($ STP $)$ 与 LNC 及 LNP 呈显著及极显著正相关关系 $(P<$ $0.01)$, 蒙古冰草叶片功能性状依赖于土壤水分情况, 干旱环境中蒙古冰草叶片 LA 较低, 而相应的 SLA、LNC 及 LNP 较高, 蒙古冰草的这些特征充分解释了为适应干旱生境而产生的保水对策。另外, 蒙古冰草 LDMC 与 土壤碳、氮间的关系可以反映植物获取资源的能力, 说明蒙古冰草能很好的适应养分贫痊的土壤环境, 而土壤 全磷对蒙古冰草叶片 LNC 及 LNP 含量贡献显著。土壤微生物生物量碳( SMBC)、氮( SMBN) 与蒙古冰草叶片 SLA、LNC 及 LNP 含量均呈极显著正相关关系 $(P<0.01)$, 这些功能性状能敏感的反映土壤中有效养分资源情 况。同时, 放线菌数量与蒙古冰草叶片 LNC 呈显著正相关, 真菌数量与其干物质含量 LDMC 呈显著负相关 关系。

与蒙古冰草相似, SW 与短花针茅 $\mathrm{LA}$ 和 LDMC 呈极显著 $(P<0.01)$ 和显著 $(P<0.05)$ 正相关关系 $(P<$ $0.01)$, 与 SLA、LNC 及 LNP 呈极显著负相关关系 $(P<0.01)$, 短花针茅能够通过提高其 SLA、LNC 及 LNP 来适 应干旱生境, 水分条件好的土壤能显著提高其叶面积和干物质含量。另外, STN、SMBC、SMBN 与 LNC 及 LNP 呈极显著正相关关系 $(P<0.01)$, 这些性状相比 LA、LDMC、SLA 对环境的反应更敏感, 说明短花针茅 LNC、 LNP 能很好地指示植物对资源的利用。相关分析显示, 土壤微生物数量与短花针茅叶功能性状均没有相 关性。

达乌里胡枝子叶片 LA 和 LNC 能很好地反映土壤水分情况, SW 越高, LA 越大、 LNC 越高。LDMC 与 SOC、TN 呈极显著负相关关系 $(P<0.01), \mathrm{LA} 、 \mathrm{LNC}$ 与 STP、SMBC、SMBN 呈显著负相关关系 $(P<0.01), \mathrm{LPC}$ 与土壤真菌数量极显著正相关 $(P<0.01)$, 与放线菌数量显著负相关 $(P<0.05)$, LDMC 与真菌数量显著负相 关 $(P<0.05)$ 。相关分析说明土壤全磷含量不利于达乌里胡枝子叶片对氮素的吸收, 研究也发现, 固氮植物达 乌里胡枝子和多年生植物蒙古冰草能很好地适应贫痊土壤环境, 蒙古冰草和短花针茅对土壤微生物生物量依 赖性强于达乌里胡枝子,蒙古冰草和达乌里胡枝子叶面积对土壤水分的敏感性更强。 
表 3 优势种叶片功能性状与土壤因子之间的相关系数

Table 3 Correlation coefficients among leaf functional traits of dominant plants and soil properties

\begin{tabular}{|c|c|c|c|c|c|c|c|c|c|}
\hline \multirow{2}{*}{$\begin{array}{l}\text { 项目 } \\
\text { Stems }\end{array}$} & \multicolumn{9}{|c|}{ 蒙古冰草 Agropyron mongolicum } \\
\hline & SW & SOC & STN & STP & SMBC & SMBN & $\begin{array}{l}\text { 细菌数量 } \\
\text { Soil bacteria }\end{array}$ & $\begin{array}{l}\text { 真菌数量 } \\
\text { Soil fungus }\end{array}$ & $\begin{array}{c}\text { 放线菌数量 } \\
\text { Soil actinomyete }\end{array}$ \\
\hline LNC & $-0.82^{* *}$ & -0.04 & -0.09 & $0.78^{*}$ & $0.98^{* * *}$ & $0.99^{* * *}$ & 0.20 & -0.48 & $0.75^{*}$ \\
\hline LPC & $-0.87^{* *}$ & 0.08 & 0.17 & $0.88^{* *}$ & $0.98^{* *}$ & $0.94^{* *}$ & 0.42 & -0.27 & 0.58 \\
\hline LA & $0.92^{* *}$ & $-0.73^{*}$ & -0.62 & $-0.69^{*}$ & $-0.70^{*}$ & -0.59 & -0.11 & -0.30 & 0.05 \\
\hline LDMC & 0.62 & $-0.82^{* *}$ & $-0.92 * *$ & -0.55 & -0.33 & -0.16 & -0.39 & $-0.71^{*}$ & 0.46 \\
\hline SLA & $-0.79^{* *}$ & 0.09 & -0.11 & 0.56 & $0.84^{* *}$ & $0.87^{* *}$ & -0.19 & -0.41 & 0.54 \\
\hline \multirow{2}{*}{$\begin{array}{l}\text { 项目 } \\
\text { Stems }\end{array}$} & \multicolumn{9}{|c|}{ 短花针茅 Stipa breviflora } \\
\hline & $\mathrm{SW}$ & SOC & STN & STP & SMBC & SMBN & $\begin{array}{c}\text { 细菌数量 } \\
\text { Soil bacteria }\end{array}$ & $\begin{array}{l}\text { 真菌数量 } \\
\text { Soil fungus }\end{array}$ & $\begin{array}{c}\text { 放线菌数量 } \\
\text { Soil actinomyete }\end{array}$ \\
\hline LNC & $-0.89^{* *}$ & 0.06 & 0.03 & $0.84^{* *}$ & $0.99^{* *}$ & $0.99^{* *}$ & 0.21 & -0.35 & 0.67 \\
\hline LPC & $-0.88^{* *}$ & 0.04 & 0.02 & $0.85^{* *}$ & $0.99^{* *}$ & $0.99^{* * *}$ & 0.17 & -0.33 & 0.66 \\
\hline LA & $0.86^{* *}$ & -0.53 & -0.64 & $-0.76^{*}$ & $-0.71 *$ & -0.59 & -0.28 & -0.38 & 0.05 \\
\hline LDMC & $0.80^{*}$ & -0.62 & $-0.73^{*}$ & $-0.79^{*}$ & -0.63 & -0.48 & -0.37 & -0.52 & 0.11 \\
\hline SLA & $-0.74^{*}$ & 0.21 & 0.26 & 0.53 & 0.68 * & 0.65 & 0.04 & -0.01 & 0.13 \\
\hline \multirow{2}{*}{$\begin{array}{l}\text { 项目 } \\
\text { Stems }\end{array}$} & \multicolumn{9}{|c|}{ 达乌里胡枝子 Lespedeza davurica } \\
\hline & SW & SOC & STN & STP & SMBC & SMBN & $\begin{array}{c}\text { 细菌数量 } \\
\text { Soil bacteria }\end{array}$ & $\begin{array}{l}\text { 真菌数量 } \\
\text { Soil fungus }\end{array}$ & $\begin{array}{c}\text { 放线菌数量 } \\
\text { Soil actinomyete }\end{array}$ \\
\hline LNC & $0.85^{* *}$ & -0.52 & -0.63 & $-0.87 * *$ & $-0.73^{*}$ & -0.60 & -0.26 & -0.38 & -0.03 \\
\hline LPC & 0.03 & 0.46 & $0.77^{*}$ & 0.04 & -0.27 & -0.42 & 0.19 & $0.86^{* *}$ & $-0.77 *$ \\
\hline LA & $0.88^{* *}$ & -0.38 & -0.52 & $-0.82 * *$ & $-0.80^{* *}$ & $-0.70^{*}$ & -0.31 & -0.23 & -0.13 \\
\hline LDMC & 0.62 & $-0.82^{* *}$ & $-0.92 * *$ & -0.55 & -0.33 & -0.16 & -0.39 & $-0.71^{*}$ & 0.46 \\
\hline SLA & 0.22 & $-0.67^{*}$ & -0.40 & -0.15 & -0.01 & 0.08 & 0.07 & -0.36 & 0.28 \\
\hline
\end{tabular}

$*$ 和 $* *$ 表示显著相关 $(P<0.05)$ 和极显著相关 $(P<0.01), ;$ LNC: 叶氮含量 Leaf nitrogen content; LPC: 叶磷含量 Leaf phosphorus content; LA: 叶面积 Leaf area; LDMC: 叶干物质含量 Leaf dry matter content; SLA: 比叶面 Specific leaf area

\section{3 讨论}

3.1 降水量对荒漠草原优势植物叶片功能性状的影响

植物功能性状作为解释变量, 对生态系统功能变化有显著的指示作用 ${ }^{[20]}$, 指示植物对异质环境的适应能 力 ${ }^{[23]}$ 。研究表明, 植物叶片功能性状受降水量的影响表现出区域和种间差异, 表现出植物叶片功能性状与降 水不相关、负相关及正相关关系 ${ }^{[23,28-29]}$ 。本研究中,增水 $50 \%$ 后 3 个优势植物 LA、LDMC 显著增大,减水 $50 \%$ 后短花针茅和达乌里胡枝子 LA、LDMC 显著减小, 对蒙古冰草 LA 影响不显著, 增、减水对短花针茅和达乌里 胡枝子 SLA 影响不显著,而减水显著提高蒙古冰草 SLA, 减水处理显著提高了蒙古冰草和短花针茅 LNC 和 LPC, 优势种叶功能性状对降水量变化表现出种间差异。由于荒漠草原区水分散失很快, 降水是制约植物生 长最重要的因子, 蒙古冰草在不同的生境中适应能力更强,其植物的叶片对环境的反应更为敏感,在干旱环境 下,可以通过有效利用有限的水分资源或者通过避免干旱的策略来实现。

3.2 降水量对荒漠草原土壤水分、养分及微生物特性的影响

降水是土壤水分最主要的来源, 它能改变土壤水分有效性, 对植物、土壤 C、N、P 及其微生物都产生了重 要影响。有研究发现 ${ }^{[38]}$, 降水通过提高土壤中 $\mathrm{N}$ 素的转移进而促进植物对 $\mathrm{N}$ 素的吸收利用, 土壤 $\mathrm{N}$ 含量与 降水量呈正相关。但水分过多会引起土壤 $\mathrm{N}$ 素淋溶, 导致土壤 $\mathrm{N}$ 含量降低。但也有研究表明, 植物和土壤 $\mathrm{C}$ 和 $\mathrm{P}$ 含量与降水量缺乏一致的相关性, 且短期内水分改变的影响难以显现 ${ }^{[11]}$ 。本研究减水处理显著降低了 土壤含水量, 但对土壤 $\mathrm{C} 、 \mathrm{~N}$ 含量影响不显著, 增水处理显著降低了土壤 $\mathrm{C} 、 \mathrm{~N}$ 含量, 对土壤 $\mathrm{P}$ 影响不显著, 增、 减水均显著减少了真菌数量, 而放线菌数量和微生物生物量碳、氮显著增加。这是由于增加降水缓解了土壤 
水分限制, 提高了土壤 $\mathrm{C} 、 \mathrm{~N}$ 矿化速率和有效性,从而刺激了微生物生长繁殖、促进了微生物量 $\mathrm{C}$ 和 $\mathrm{N}$ 积 累 ${ }^{[39]}$, 而极端干旱 (减水 $50 \%$ ) 时微生物和植物存在 $\mathrm{C}$ 和 $\mathrm{N}$ 竞争, 土壤 $\mathrm{C} 、 \mathrm{~N}$ 矿化速率下降, 土壤微生物生物 量积累更多,说明土壤中 $\mathrm{C} 、 \mathrm{~N}$ 有效性及微生物活性与降水密切相关,减少降雨能够积累更多的土壤养分、避 免微生物活性受降水刺激, 但土壤养分有效性和可供植物吸收利用程度下降。然而,过高降雨量易导致养分 淋溶损失、微生物呼吸受阻不利于微生物量的积累 ${ }^{[11]}$ 。另外, 降水对植物功能性状的影响同时受气候、植被、 土壤性质综合作用,需要综合考虑不同因子对植物生长的影响。

3.3 荒漠草原优势植物叶片功能性状与土壤因子间的相关性

植被-土壤系统物质循环是以微生物为中介在植物和土壤之间相互转换的, 降水对生态系统营养元素平 衡的影响, 需要将叶片功能性状、土壤性状和微生物活动综合考虑, 从而更好地揭示荒漠草原各组分间元素的 传递规律和调节机制。澳大利亚东南部的多年生植物比叶面积与降水和土壤总含磷量呈正相关, 养分限制引 起 SLA 下降, 植物的 SLA 对环境的反应比 LDMC 更敏感 ${ }^{[40]}, \mathrm{Ryser}^{[41]}$ 的研究也发现, 部分植物的 LDMC 对氮 素营养反应不敏感,但 Wilson ${ }^{[42]}$ 等在比较了英格兰地区 769 种植物的 SLA 和 LDM C 后认为 LDMC 比 SLA 更 好的指示植物对资源的利用。本研究 3 种优势植物 LA 均与土壤水分显著正相关, 蒙古冰草和短花针茅通过 提高 SLA、LNC 及 LNP 来适应干旱生境, 蒙古冰草 LA 和 LDMC 与土壤 C、N 呈显著负相关, 表明蒙古冰草能 够适应养分贫㾑土壤, 当土壤比较贫㾑时, 较低的绿叶养分浓度有助于延长养分在植物体内的滞留时间, 从而 降低植物对土壤养分的依赖性, 因此是植物适应贫㾑生境的有效策略。蒙古冰草和短花针茅 LNC 及 LNP 能 够敏感表征土壤 $\mathrm{P} 、$ 微生物生物量 $\mathrm{C} 、 \mathrm{~N}$ 有效性, 豆科植物达乌里胡枝子 SLA 和 LDMC 与土壤 $\mathrm{C} 、 \mathrm{~N}$ 呈显著负相 关, 在贫㾑土壤中, 达乌里胡枝子通过自我调节养分利用策略来适应 $\mathrm{C} 、 \mathrm{~N} 、 \mathrm{P}$ 含量较低和微生物活性较低的 生境, 从而决定其在群落中的优势种位置。

\section{4 结论}

本文通过分析不同降水梯度下盐池县荒漠草原优势植物叶片功能性状的变化规律, 以及植物叶片功能性 状与土壤养分、水分、微生物间的关系, 揭示干旱区优势植物对环境变化的响应和适应策略,得出以下结论:

蒙古冰草叶片对环境的反应更为敏感, 在干旱环境下, 蒙古冰草和短花针茅通过提高 SLA、LNC 及 LNP 来适应干旱生境, 能够敏感表征土壤 P、SMBC、SMBN 有效性, 蒙古冰草和短花针茅可以通过有效利用有限的 水分资源或者通过避免干旱的策略来实现,达乌里胡枝子通过提高各功能性状大小来适应 $\mathrm{C} 、 \mathrm{~N} 、 \mathrm{P}$ 含量较低 和微生物活性较弱的生境。多年生禾本科植物蒙古冰草和短花针茅 LNC、LPC、LA、SLA、及 LDMC 均能很好 的指示植物对资源的利用和对土壤水分的敏感性,而在贫痊的土壤环境下,豆科植物达乌里胡枝子通过提高 干物质含量 LDMC 的策略来适应环境, 良好的土壤水分环境能增大其叶面积和提高植物对氮的吸收利用。

\section{参考文献 (References) :}

[ 1 ] 于贵瑞, 王秋风, 于振良. 陆地生态系统水-碳耦合循环与过程管理研究. 地球科学进展, 2004, 19(5): 831-839.

[ 2 ] 苗百岭, 梁存柱, 韩芳, 梁茂伟, 张自国. 内蒙古主要草原类型植物物候对气候波动的响应. 生态学报, 2016, 36(23): 7689-7701.

[ 3 ] Knapp A K, Ciais P, Smith M D. Reconciling inconsistencies in precipitation-productivity relationships: implications for climate change. New Phytologist, 2017, 214(1): 41-47.

[ 4 ] Chen J, Xiao G L, Kuzyakov Y, Darrel Jenerette G, Ma Y, Liu W, Wang Z F, Shen W J. Soil nitrogen transformation responses to seasonal precipitation changes are regulated by changes in functional microbial abundance in a subtropical forest. Biogeosciences, 2017, 14(9) : $2513-2525$.

[ 5 ] Zhou X H, Talley M, Luo Y Q. Biomass, litter, and soil respiration along a precipitation gradient in Southern Great Plains, USA. Ecosystems, 2009, 12(8): 1369-1380.

[ 6 ] 邹慧, 高光耀, 傅伯杰. 干旱半干旱草地生态系统与土壤水分关系研究进展. 生态学报, 2016, 36(11): 3127-3136.

[ 7 ] Shi Y, Wang Y, Ma Y, Ma W, Liang C, Flynn D F B, Schmid B, Fang J, He J S. Field-based observations of regional-scale, temporal variation in net primary production in Tibetan alpine grasslands. Biogeosciences, 2014, 11(7) : 2003-2016.

[8] 李小雁. 干旱地区土壤-植被-水文耦合、响应与适应机制. 中国科学: 地球科学, 2011, 41(12): 1721- 1730.

[ 9 ] 张存厚, 王明玖, 乌兰巴特尔, 姜新华. 内蒙古典型草原地上净初级生产力对气候变化响应的模拟. 西北植物学报, 2012, 32(6): 
1229- 1237.

[10］龙慧灵, 李晓兵, 黄玲梅, 王宏, 魏丹丹. 内蒙古草原生态系统净初级生产力及其与气候的关系. 植物生态学报, 2010, 34(7) : 781-791.

[11］黄菊荣, 余海龙, 刘吉利, 马飞, 韩丕. 控雨对荒漠草原植物、微生物和土壤 C、N、P 化学计量特征的影响. 生态学报, 2018, 38(15)： 5362-5373.

[12] 吕晓敏, 王玉辉, 周广胜, 许振柱, 陈军, 谭丽萍, 刘涛. 温度与降水协同作用对短花针茅生物量及其分配的影响. 生态学报, 2015, 35 (3) : 752-760.

［13］董明伟，喻梅. 沿水分梯度草原群落 NPP 动态及对气候变化响应的模拟分析. 植物生态学报, 2008, 32(3): 531-543.

[14］白永飞. 降水量季节分配对克氏针茅草原群落初级生产力的影响. 植物生态学报, 1999, 23(2): 155-160.

[15] 张峰, 周广胜, 王玉辉. 内蒙古克氏针茅草原植物物候及其与气候因子关系. 植物生态学报, 2008, 32(6): 1312- 1322.

[16] 陈佐忠, 黄德华. 自然条件下大针茅草原几种主要植物氮、磷、钾、铁含量的季节动态. 植物生态学与地植物学学报, 1989, 13 (4)： 325-331.

[17] 王义凤, 姜恕. 干旱气候对大针茅草原的群落结构和土上部分生物量的影响. 植物生态学报, 1982, 6(4): 333-338.

[18] 马文红, 方精云. 中国北方典型草地物种丰富度与生产力的关系. 生物多样性, 2006, 14(1): 21-28.

[19] 张彩虹, 张雷明, 刘杏认, 辛晓平, 李胜功. 呼伦贝尔草甸草原优势种贝加尔针茅根系组织和地上部分调落物的分解. 植物生态学报, 2011, 35(11): 1156-1166.

[20］孟婷婷, 倪健, 王国宏. 植物功能性状与环境和生态系统功能. 植物生态学报, 2007, 31(1) : 150-165.

[21] 周鹏, 耿燕, 马文红, 贺金生. 温带草地主要优势植物不同器官间功能性状的关联. 植物生态学报, 2010, 34(1): 7-16.

[22] 李丹, 康萨如拉, 赵梦颖, 张庆, 任海娟, 任婧, 周俊梅, 王珍, 吴仁吉, 牛建明. 内蒙古羊草草原不同退化阶段土壤养分与植物功能性 状的关系. 植物生态学报, 2016, 40(10): 991-1002.

[23] 尧婷婷, 孟婷婷, 倪健, 阎顺, 冯晓华, 王国宏. 新疆准噶尔荒漠植物叶片功能性状的进化和环境驱动机制初探. 生物多样性, 2010, 18 (2) : 188-197.

[24] 雷羚洁, 孔德良, 李晓明, 周振兴, 李国勇. 植物功能性状、功能多样性与生态系统功能: 进展与展望. 生物多样性, 2016, 24(8)： 922-931.

[25] 杨继鸿, 李亚楠, 卜海燕, 张世挺, 齐威. 青藏高原东缘常见阔叶木本植物叶片性状对环境因子的响应. 植物生态学报, 2019, 43(10)： 863-876.

[26] 刘晓娟, 马克平. 植物功能性状研究进展. 中国科学: 生命科学, 2015, 45(4) : 325-339.

[27] 王晶, 赵文武, 刘月, 贾立志. 植物功能性状对土壤保持的影响研究述评. 生态学报, 2019, 39(9) : 3355-3364.

[28］冯秋红，史作民，董莉莉. 植物功能性状对环境的响应及其应用. 林业科学，2008，44(4)：125-131

[29] 赵新风, 徐海量, 张鹏, 张青青. 养分与水分添加对荒漠草地植物钠猪毛菜功能性状的影响. 植物生态学报, 2014, 38(2)：134-146.

[30］龚时慧, 温仲明, 施宇. 延河流域植物群落功能性状对环境梯度的响应. 生态学报, 2011, 31(20): 6088-6097.

[31] 杨士梭, 温仲明, 苗连朋, 戊德辉, 花东文. 黄土丘陵区植物功能性状对微地形变化的响应. 应用生态学报, 2014, 25(12): 3413-3419.

[32] 田大栓, 包祥, 关其格, 潘庆民. 内蒙古草原 3 种针茅属植物不同组织水平的生物量生殖分配. 植物生态学报, 2009, 33(1): 97-107.

[33］苏宏新, 马克平. 生物多样性和生态系统功能对全球变化的响应与适应: 协同方法. 自然杂志, 2010, 32(5) : 272- 280.

[34] 间宝龙, 王占文, 王悦华, 康静, 宋晓辉, 王忠武, 韩国栋. 短期降雨改变对荒漠草原植物群落特征的影响. 草业科学, 2018, 35(5)： 1004-1012.

[35] 宋乃平, 王兴, 陈林, 薛毅, 陈娟，随金明，王否，杨新国. 荒漠草原“土岛”生境群落物种共存机制. 生物多样性，2018，26(7)： 667-677.

[36] 鲁如坤. 土壤农业化学分析方法. 北京: 中国农业科技出版社, 2000.

[37] 关松荫. 土壤酶及其研究法. 北京: 农业出版社, 1986.

[38] 杨山, 李小涁, 王汝振, 蔡江平, 徐柱文, 张玉革, 李慧, 姜勇. 氮水添加对中国北方草原土壤细菌多样性和群落结构的影响. 应用生态 学报, 2015, 26(3): 739-746.

[39] Xu Z Z, Hou Y H, Zhang L H, Liu T, Zhou G S. Ecosystem responses to warming and watering in typical and desert steppes. Scientific Reports, 2016, 6(1): 34801 .

[40] Fonseca C R, Overton J M, Collins B, Westoby M. Shifts in trait-combinations along rainfall and phosphorus gradients. Journal of Ecology, 2000, 88(6): 964-977.

[41] Ryser P. The importance of tissue density for growth and life span of leaves and roots: a comparison of five ecologically contrasting grasses. Functional Ecology, 1996, 10(6): 717-723.

[42] Wilson P J, Thompson K, Hodgson J G. Specific leaf area and leaf dry matter content as alternative predictors of plant strategies. New Phytologist, $1999,143(1): 155-162$. 